\title{
ETNOGRAFIA CUSTOMIZADA: TEMPO E ESPAÇO SOB A ÓTICA EMPRESARIAL
}

\author{
Luciano D'Ascenzi ${ }^{1}$ \\ Luciana Leite Lima
}

Resumo: Relato de aplicação do desenvolvimento etnográfico denominado etnografia customizada, junto a uma softwarehouse. Adequação a contextos organizacionais contemporâneos dirige esforços de ajuste nas dimensões tempo e espaço etnográficos em acordo ao lugar em Geertz. A "teoria nativa" direciona a pesquisa que, por sua vez, é incorporada aos processos decisórios locais, auxiliando mudanças em direção à humanização e democratização das relações de trabalho. A metodologia realiza movimento transdisciplinar, configurando-se numa contribuição simultânea em diversos campos das ciências sociais, básica e aplicada.

Palavras-chave: inovação, mudança, cultura, liderança, organização.

Abstract: Account of an ethnographic development application, the customized ethnography, within a software house. Suited to contemporary organizational contexts, it directs efforts to adjust the ethnographic dimensions time and space, according to Geertz's concept of place. "The native theory" directs the research, which is incorporated into the decision-making processes, supporting local changes toward the humanization and democratization of labor relationships. This methodology conducts to a transdisciplinary movement, by setting in a simultaneous contribution in social sciences, basic and applied.

Keywords: innovation, change, culture, leadership, organization.

${ }^{1}$ Doutor em Ciências Sociais.

${ }^{2}$ Professora do Departamento de Sociologia do Instituto de Filosofia e Ciências Humanas da Universidade Federal do Rio Grande do Sul (UFRGS). 
$\mid 12$ |

Etnografia customizada: tempo e espaço...

\section{Objetivo e contextualização}

Artigo deriva de desenvolvimento teórico-metodológico a partir de pesquisa empírica realizada no escopo do programa de doutorado em Ciências Sociais do IFCH/ Unicamp (D'ASCENZI, 2010) $)^{3}$ com bolsa CAPES. Desta feita, escolhemos discutir a questão da tradução (GEERTZ, 1998), junto à qual destacamos um problema inerente à manipulação de terminologias supostamente conhecidas.

A MATERA System ${ }^{4}$ é uma softwarehouse criada nos anos 1980, e vem operando pela diversidade de períodos que caracterizam o setor: desde "a era cowboy", época em que o setor automatizava rotinas artesanalmente, sob medida; passando pela "fábrica de softwares", seu ideal de produção impessoal e em série; até os dias de hoje, quando a última passa a sofrer contestação. Além de discurso calcado na "racionalidade econômica" (SIMON, 1979), a MATERA apresentava traços dos três períodos.

$\mathrm{Na}$ fase "cowboy" o mercado exigia que o programador focasse o cliente e suas rotinas. $\mathrm{Na}$ "fábrica de software" as soluções são padronizadas e o programador é um especialista, sem contato com o cliente. Em termos biográficos, poucas pessoas atuavam desde a primeira fase.

Complementando, a empresa é referência junto ao pólo tecnológico de Campinas, um dos maiores do país. Em parte, isso se deve à longevidade - muitos donos de outras companhias ali iniciaram carreira. Por fim, os principais valores praticados eram a meritocracia e a transparência.

\section{Processo de Customização: Uma empresa de nerds}

A primeira fase do método objetivou testar aproximação de universos, científico e empresarial. Assim, franquear acesso

\footnotetext{
${ }^{3} \mathrm{http}: / / \mathrm{www} \cdot$ bibliotecadigital.unicamp.brdocument/?code=000477109\&opt=4....

${ }^{4}$ http://www.matera.com.br.
} 
ao trabalho de campo implicou em convencer a gestão local da possível complementaridade de objetivos, de que a pesquisa acadêmica poderia responder alguma questão gerencial crítica, sem solução anterior. Além disso, o tempo também passa por processo de ajuste, uma vez que o tempo gerencial é bem mais curto que o etnográfico. Assim, a segmentação do objeto teve início com o compartilhamento da autoridade etnográfica para a formulação da pergunta de pesquisa.

Passada a fase do "o quê você quer fazer aqui?" e do "o que eu ganho com isso?", o diálogo evoluiu a ponto de focar dois programas tidos como problemáticos: "Meu cliente, meu amigo" e o "Programa de participação nos lucros". A dificuldade estaria relacionada com o comportamento antisocial dos setores denominados, genericamente, de "engenharias". Tratava-se das pessoas que eram responsáveis pela atividade fim da empresa, soluções em informática. O conjunto comportamental em questão foi ilustrado pelo estereótipo do nerd - falta de habilidade e impaciência no trato interpessoal, mas bom relacionamento quando o assunto é de seu interesse, hardware de última geração ou linhas de código de programação. Somava-se a isso o desenho de um ambiente interno onde o trabalho do outro seria mais fácil e mais reconhecido, resultando em "visão de injustiça" quanto à distribuição dos frutos do trabalho coletivo.

À guisa de resultado do processo de customização, reportar-nos-ia à gerente de Recursos Humanos (RHU); fomos alocados em mesa junto ao lugar da pesquisa; conexão de intra e internet; acesso à documentação relativa; e, por fim, a oportunidade de entrevistar amostra de colaboradores conjuntamente selecionados. Por outro lado, apresentaríamos laudo com respostas e sugestões em trinta dias.

\section{O trabalho de campo}

A MATERA estava instalada em prédio com dois pisos, sendo que, grosso modo, o superior abrigava áreas mais ligadas à gestão 
e o inferior, mais ligadas ao lugar de pesquisa, as "engenharias". Estas em um grande salão bem iluminado, climatizado e sem janelas. Um espaço todo circundado por salas de seus dirigentes imediatos, igualmente sem visão exterior. Já os profissionais, divididos em setores, possuíam amplas mesas do tipo estação de trabalho, perfazendo vários conjuntos contíguos separados por divisórias baixas, que permitiam boa visualização coletiva, mesmo quando sentado.

A empresa ultrapassou os 100 colaboradores em 2000 e, desde 2008, é uma sociedade anônima de capital fechado com mais de 200 "profissionais", conforme denominação local. Além disso, era certificada CMMI " "nível 2" e figurava no ranking das 100 "Melhores Empresas para Trabalhar", sendo 16 em TI \& Telecom ${ }^{6}$.

Hierarquicamente, estava organizada em cinco níveis: presidência, diretoria, gerência, coordenação e analistas. Sendo que - para possibilitar a acomodação de promoções para esses últimos, mesmo quando "não se identificassem" com "funções de liderança" - havia os "arquitetos" e os "especialistas", no mesmo nível que a baixa gerência (carreira em Y). De volta ao organograma tradicional, ele se desenrolava em árvore a partir de cinco diretorias, embora algumas áreas, como o RHU, estivessem ligadas à presidência. $\mathrm{O}$ mesmo ocorria com os setores ligados à inovação. Naquele particular, o RHU tem um claro papel estratégico e "função de staff" (atividade meio), em contraposição a "responsabilidade de linha" (atividade fim), a cargo das áreas operacionais específicas (CHIAVENATO, 1999). Uma divisão de trabalho ainda não totalmente compreendida em toda a empresa, apesar do ambiente de transparência reafirmado, bem como da facilidade de acesso à informação.

A comunicação conta com jornal interno on line e wiki. Esta última parecia proporcionar apoio orgânico-estrutural, ao disponibilizar informação ligada à organização e trabalho da

\footnotetext{
${ }^{5}$ Detalhes em http://www.sei.cmu.edu/cmmi/index.html.

${ }^{5}$ Detalhes em http://www.greatplacetowork.com.br/best/list-brit.htm.
} 
empresa. Tipicamente, trata-se de uma forma colaborativa e, portanto, sempre inacabada de apresentação de documentos, visando à edição coletiva em apresentação e conteúdo. Já o jornal on line, de periodicidade mensal, encontrava-se em sua $51^{\text {a }}$ edição. Seus exemplares estavam estruturados a partir de uma primeira página, e respectivos links de acesso, onde se visualizava todas as notícias da edição, além de seções usuais, presentes em todos os números. Configurou-se em excelente banco de informações para pesquisa, sendo visualizado por boa parte das pessoas. Suas matérias eram colhidas internamente, consubstanciandose num poderoso meio de comunicação e entendimento daquele meio cultural. Contava com editorial, normalmente, escrito por um dos dirigentes da empresa, que parecia manter as pessoas posicionadas quanto às questões mais estratégicas. Sugeria inserir mais segurança e transparência no ambiente geral, ajudando na reprodução de algumas das características corporativas. Quanto a isso, os editoriais contavam com os maiores "índices de audiência". Nota-se que sua ausência, em raras oportunidades, comprometia a utilização do meio de comunicação como um todo, dada a queda no número de visualizações após tais ocorrências.

As qualidades e quantidades encontradas no interior da empresa consubstanciavam funcionalidade determinada daqueles espaços. Significativamente, tudo estava disponível para diversos tipos de análise complementar, incluindo a nossa. Contudo, além das permissões, a qualidade do acesso dependia do domínio do idioma local, eminentemente funcionalista. Realizada a tradução do discurso e sua comprovação prática, a etnografia customizada rezou em complementar a funcionalidade documentada por meio da inclusão de outros elementos conceituais, desde que relevantes à explicação da pergunta de pesquisa. $\mathrm{O}$ adensamento das descrições passou então pela percepção de elementos de intencionalidade, linguisticalidade, estrategicidade, normatividade e consensualidade. Grosso modo, havia uma plataforma funcional dada e, complementarmente, uma descrição densa por realizar.

Iniciando a aproximação etnográfica a partir do ponto de observação, passamos à investigação daquele inesgotável material 
| 16 |

Etnografia customizada: tempo e espaço..

real-virtual. Queria entender e qualificar a organização do trabalho e seus processos internos, ao mesmo tempo em que ia percebendo as estruturas sociais informais e seus fluxos, tempos, falas, recorrências etc. Afinal, precisava perceber, in loco, a existência e nível de marginalidade/ inserção dos comportamentos relatados como indesejáveis pela gestão e que traduzi, já em campo, como concernente à categoria integração. Inicialmente, algumas perguntas me guiaram: o problema relatado era passível de observação? Em que nível? Qual seria o funcionamento das categorias pesquisadas? Como eram ativadas e apoiadas?

No decorrer daquelas semanas, percebi que todas as manhãs, paulatinamente, o grande salão térreo ia se enchendo de pessoas. Alguns chegavam muito cedo, antes das sete horas, enquanto outros apenas ao final da manhã, ficando até tarde da noite. Parecia não haver hora fixa para o trabalho, confirmando o regime de horário e a flexibilidade discreta reinante no ambiente, completamente preenchido ao final da manhã. Tudo sem alarde ou alterações dignas de nota.

À primeira vista, o modus operandi era a impossibilidade na identificação de traços comuns na aparência dos frequentadores daquele espaço. Alguns se movimentavam apressadamente enquanto outros nem tanto. Além disso, trajavam-se e tinham costumes heterogêneos, numa mistura de cabelos longos e curtos, camisas sociais e camisetas, salto alto e tênis etc, sem que tais questões qualificassem algum tipo de fronteira. Havia apenas essa espécie de discrição e flexibilidade. Tidos pelas outras áreas da empresa como introspectivos, silenciosos, de linguagem objetiva e comportamento anti-social, isso não era observável no interior de seus respectivos grupos, onde revelavam outras características, não demonstrando qualquer automatismo. Ao invés de silenciosos e introspectivos, cordatos, como que dosando a energia despendida em cada gesto, parecendo centrados em suas atividades e prazos de trabalho, metodicamente quantificados pela gerência de projetos e por eles administrados.

Divididos em breves pequenos grupos, que se recompunham em diferentes momentos, conversavam de maneira discreta, mas 
descontraída, majoritariamente sobre TI, cobrindo assuntos de trabalho ou privados. Contudo, não se furtavam em conversar sobre temas universais, como futebol ou política. Isso, no cafezinho, almoço, ao redor de um banco ou em frente à tela de seus PCs. Tudo sem demonstrar grandes alterações de comportamento, sem falas paralelas ou interrupções, ouvindo e esperando por sua vez.

As interações pareciam regidas por certa cerimonialidade ritualmeritocrática, mesmoem rodasinformais.Umcomportamento controlado pelos próprios integrantes, que pareciam categorizar o que é, e o que não é, "barulho". No geral, a atmosfera podia ser caracterizada pela flexibilidade e informalidade reinantes, havendo espaço para todo tipo de perfil, desde que respeitados os limites.

Mesmo sendo característica normalmente associada à area de informática, esse caso particular tinha pelo menos uma explicação prática. Ocorre que ao longo de sua história a empresa viu-se obrigada a se adaptar à crescente carência de mão-deobra especializada. Mesmo havendo iniciado suas contratações, exclusivamente, nos melhores e consagrados centros de ensino e pesquisa do estado, aos poucos foi necessário afrouxar suas exigências. Hoje, contenta-se com uma boa formação de nível médio ou ensino técnico. Os únicos obstáculos institucionais à entrada de novos profissionais dizem respeito, primeiramente, à necessidade ou não da imediata contratação. Somado a isso, vem o conhecimento especializado nas ferramentas de trabalho, baseadas nas apostas tecnológicas, passadas e presentes, de forte presença ou crescente utilização: SQL e JAVA7 .

Até essas [atendimento inicial: nível 1], a gente tem uma dificuldade de contratação, porque não é uma simples telefonista, ela exige um certo conhecimento de habilidade de registro de chamada... corretamente na fila de atendimento... mas, esquecendo essas duas profissionais [nível 1], todos os demais têm que ser técnico, aliás, hoje, o primeiro requisito que a gente

\footnotetext{
${ }^{7}$ Linguagem de programação baseada em objetos e ligada à internet.
} 
$|18|$

Etnografia customizada: tempo e espaço...

\begin{abstract}
cobra numa contratação de um profissional pra central de atendimento é ele tirar dez na prova de técnica nossa: técnica de programação [...] então, quando a gente aplica uma prova por exemplo pra alguém que vai entrar na área de implantação ou de operação... ou de atendimento, é essa prova de SQL; esse é o base porque essa... é aí que está toda a inteligência, em todos os sistemas que a gente desenvolve.
\end{abstract}

Isso ajudava a criar e reproduzir outra característica local, uma tecnomeritocracia específica, cujo vigor, podendo relativizar a estrutura formal, além de possibilitar, não raro, novas interpretações das categorias locais, visualizáveis por meio de redes sociais de cunho egocêntrico ${ }^{8}$ (BARNES, 1969). Quanto a isso, foi curioso perceber certa variedade de Alfas em uma mesma rede ${ }^{9}$. Uma possível explicação estaria ligada ao conteúdo (tecnológico) do sinal ativado, já que parece existir grande especialização, mesclada à hierarquia, além da variedade de interesses particulares. Por isso, qualquer explicação passa, necessariamente, pela característica tecnomeritocrática recorrente. Em seu limite, o plano técnico relaciona-se bem com hardwares e pessoal afim, ao mesmo tempo em que revela pouco interesse quanto à real aplicação de seu trabalho, seja pelo cliente, seja por outras áreas da empresa.

Como primeira constatação, percebi que havia uma mesma visão disseminada, tanto em TI quanto externa a ela, com potencial para gerar fronteira identitária (RUBEN, 1986): "nerds" seriam pessoas caladas, de difícil socialização, agressivamente objetivos, que preferiam o relacionamento com máquinas e linhas de código a pessoas. Um estigma que parecia estar bem disseminado, já que muito repetido e, mesmo, não contestado por suas "vítimas". Por outro lado, recebiam a licenciosidade derivada desses predicados. Consubstanciava-se, por exemplo, na possibilidade de permanecer

\footnotetext{
${ }^{8}$ Os impulsos que ativam a estrutura partem e/ou convergem de um dos elos, chamado de Alfa.

${ }^{9} \mathrm{Ou}$ tratar-se-iam de redes sobrepostas por diferentes componentes tecnológicos ou hierárquicos?
} 
indiferente frente às solicitações ou programas de mudança não automatizados, como que cobrando contrapartida pela personalidade imputada. Portanto, acreditavam numa situação estável, desde que cumprissem seus prazos em suas funções de programação, estas sim de real responsabilidade. Quanto às outras questões, abria-se a possibilidade de "administrar a pressão", dadas as armas do estigma, como que escolhendo aquilo que seria ou não relevante. "Reivindicar uma identidade é construir poder" (Castells, 2008, p. 235).

Tais traços, mesmo traduzidos como limitações do perfil específico, mais que tolerados, eram tidos e tratados como um dado por "especialistas" do setor de TI e RH. Mesmo porque, justificavam-se, tratar-se-ia de profissão muito demandada pelo mercado, não faltando oportunidades de emprego alternativo àqueles jovens. Paradoxalmente, mesmo parecendo aceitar que "programadores são mesmo assim", havia no ar clara consciência do conteúdo, quase que, esquizofrênico contido naquele tipo de explicação vis-à-vis o sentimento de impotência causado por aquele "fato", tido como inevitável.

O problema relatado era relacionalmente dirigido às mais diversas direções. Assim, no RHU significava que alguns instrumentos da área não eram passíveis de aplicação local; na área comercial, que certos problemas, que poderiam ser resolvidos rapidamente, deveriam seguir rito mais demorado e cerimonioso; etc. Coletiva e estrategicamente, tinha-se: dado o imperativo de ganhos marginais de produtividade, como desarmar situações indesejadas possivelmente construídas pelo comportamento descrito? Como deveria ser um programa que pretendesse atenuar essa característica, dado o formato preferencialmente utilizado, via intencionalidade formal?

Por outro lado, o estereótipo citado também parecia uma impressão de pessoas de outras áreas externas que, por uma razão ou outra, valiam-se apenas do olhar distante, demonstrando pouca ou nenhuma relação pessoal com "as engenharias", normalmente, referenciados por essa peculiar forma coletiva. Por seu turno, além de não demonstrar qualquer preocupação, os tais nerds pareciam 
$|20|$

Etnografia customizada: tempo e espaço...

apreciar a identificação. Um informante dali, assim respondeu à provocação de que a atividade de programação fosse muito automática:

Teve, no passado [...] se falava muito como conceito, né, em "crise de software", por quê? Por que dá pra você fazer um prédio tão grande e você vai fazer um software grande e tem tanta dor de cabeça? [...] então, isso, foi motivo de estudo de muita gente, empírico ou não. Os caras chegaram a algumas conclusões, que hoje a gente tem, na verdade, meio que um guarda-chuva, que tem várias denominações, mas basicamente, o pessoal denomina Ágil, mas tem influência também do modelo Toyota [...] $\mathrm{Na}$ verdade, não dá pra automatizar que nem uma linha de produção [...] Isso é uma falácia [...] assim, grande parte dos problemas, na realidade, vem dos aspectos, assim, humanos [...] esse tal de Ágil que eu estava falando, que é uma resposta [...] tem os princípios [...] Mas quando você fala de automatizar, principalmente software, eu acho que tem de entender bem o que é... tem que definir os termos. Você consegue delimitar um processo ali ou algumas práticas [...] existem pessoas fazendo software e elas funcionam melhor em certos ambientes [...] você para de tratar as pessoas como máquina, aí o negócio começa a andar [...] por exemplo, uma das críticas severas à CMMI é que ela simplesmente esquece que tem gente que faz as coisas, parece que são um bando de robôs, entendeu? Você passa pra pessoa uma certificação, [e diz:] 'Esta certificação está certa, cara! Tem que fazer'; e não funciona assim na prática, nunca funcionou, sabe? As vezes que deram certo é porque teve alguém que deu o sangue em algum ponto.

\section{E ainda noutra situação:}

É que, na verdade, não é só a parte técnica, né? Tem a parte de processo também. Quer dizer, como é que se desenvolve; como é que você coloca um bando de pessoas...? A princípio... né? Como é que faz pra eles 
andarem pro mesmo lado e, no final, meio que por mágica, sai um produto rodando né? E rodando, quer dizer, que eu nem precise rever; o conceito de pronto, né? [...] Mas, de qualquer forma, a gente sempre tem interação muito grande com as pessoas do projeto, assim... às vezes, não é tão agradável, né? Porque às vezes tem que... as outras pessoas não mudam... Por definição, as pessoas sempre seguem... a inércia, né? Sempre tem a inércia, as pessoas só querem fazer: ah, não, eu estou acostumado a fazer isso. Então, assim, a gente sempre tem que quebrar um pouco ali o pau, vamos falar assim, mas é... mas, assim, eu, pessoalmente, assim, eu interajo com a pessoa que trabalha com a mesma gama de tecnologia, eu interajo muito, assim, tipo, a tal ponto de eu chegar assim, meio do nada, chegar lá: o que que você está fazendo, sabe? É coisa meio incisivo mesmo, se não, não funciona, não é? Que é muito fácil a entropia aumentar. A entropia, uma das leis da termodinâmica, né? Ela aumenta facilmente, então... assim: você combina que vai fazer o negócio de um jeito e você deixa o pessoal lá, tipo um projeto inteiro, fazendo. E, no final, sai tudo diferente; aí quando você vai dar a manutenção, está tudo diferente do que as pessoas achavam, né? 'Nossa, agora está mais caro!' Então, a interação é grande, tá.

No conjunto, portanto, muitos dos estigmas também tratavam de características distintivas unificadoras, mas que não sobreviviam à observação sistemática, esta sim, reveladora da diversidade de redes de significado local $^{10}$, que comportavam interesses díspares.

Do ponto de vista relacional, era possível perceber certa manipulação a partir de algumas daquelas expectativas, segundo o contexto. Mesmo porque, como tal, qualquer comportamento esperado tende a gozar de certa autonomia e complacência, conforme o caso, numa implacável classificação quanto ao que vem

${ }^{10}$ Entendida como organização de significados em redes sociais, conforme em Barnes (1969). 
a ser normal (FOUCAULT, 2003). Assim, aqueles jovens profissionais eram acusados de gerar receio à aproximação de pessoas de outras áreas da empresa. Estes últimos alegavam que o contato exigia preparo, exatidão, concisão, clareza, enfim, cansava, era "por demais". Se possível, era mais fácil evitá-los. Por seu turno, o pessoal das engenharias parecia não se incomodar, senão até apreciar o distanciamento relativo. $\mathrm{O}$ fato é que a fronteira parecia duplamente aceita.

Independentemente do nível de consciência ou intenção, o fato é que muitas das características encontradas demonstraram mecanismos reforçados, alimentado ou limitados, continuamente, pelos instrumentos de gestão local. Estes formavam conjunto homogêneo centrado/ iniciado no indivíduo, seu estoque de conhecimento específico que, em última instância, vem determinar o status junto ao grupo, tanto formal quanto informalmente. E isso, desde a entrada e desenvolvimento de novos e antigos colaboradores até o plano estratégico.

Portanto, o trabalho apontava para a responsabilidade da direção da empresa como a causadora da própria queixa. Formava-se então a seguinte questão: qual o nível de consciência da gestão sobre sua participação na formação dessa fronteira identitária indesejada? Nossa pergunta de pesquisa seria derivada de uma autocrítica ou a gestão não estaria sequer consciente de seu papel?

\section{Integração: Mais um limite à racionalidade funcionalista}

O enfoque funcionalista encontrado na teoria das organizações opera a partir de descrições sumárias de comportamentos em meio a estruturas, objetivando estabelecer relações de dependência e/ou de sequencialidade entre variáveis. No limite, uma prática que permite classificar descrições funcionais por meio da emissão de juízo de valor políticohierárquico. Assim, opera recortes relacionais de maneira 
incompleta, tendo em vista classificar os elos de rede por meio de dicotomias totalizantes. Num o certo, noutro o errado.

Ao tomar tais conclusões, dadas como ponto de partida, a etnografia customizada passa a problematizá-las, perscrutando relações entre sujeitos com algum poder de agência. Isto é, com livre-arbítrio para decidir se, quando e como irão ou não reproduzir determinada estrutura, com ou sem mudança, em acordo a uma visão de mundo e prerrogativas políticas próprias. Também permite avaliar o vigor da estrutura, em termos de limiaridade (TURNER, 1974). Uma relativização necessária ao aprofundamento da análise de contextos de ação específicos, que pode ser empreendida em termos de tempo e espaço.

Dessa maneira, tratamos de situações em que agentes sociais - portadores de razões e lógicas distintas e legítimas, isso não está em questão - relacionam-se em níveis variáveis de liberdade de ação. Algo que implica, senão na necessidade, ao menos, na possibilidade de (re)interpretações diferentes frente ao mesmo conjunto-de-ação (BARNES, 1969). Paralelamente, dada a subjetividade realçada, haveria indeterminadas possibilidades e níveis relativos de (in) consciência quanto a fenômenos e significados, especialmente, quando vinculados à prática cotidiana.

Por exemplo, um ator poderia imputar "culpa" ao outro, quanto à geração de determinado contexto de ação, sem que o outro assim perceba. Nesse caso, tratar-se-ia de algum nível de conflito. Configuraria ainda, um caso em que o observador desarmado, após ouvir os dois lados, não conseguiria determinar qual deles, afinal, é a "vítima", já que ambos reclamam da atitude do outro e apresentam razões para tal. Algo que, descartada a consensualidade, poderia desencadear algum nível de violência, mesmo que por via normativa. Nesse caso, tomaria a feição decorrente dos atributos de poder de cada lado, caracterizada por crescentes níveis de detalhes que só a empiria poderia revelar. Tudo isso em tese. Já no lado real, um informante assim explicou a relação: 
$|24|$

Etnografia customizada: tempo e espaço...

\begin{abstract}
A primeira coisa que eu falo quando eu entro no projeto, quando as pessoas não me conhecem, eu falo assim: olha, antes de mais nada, este projeto não é pra fazer amizade, cara. Isso causa choque nas pessoas, não é? [...] a amizade é um efeito colateral [...] você não pode achar que você vai e... vou ser amigo daquela pessoa! Quer dizer, isso é coisa da vida, não é? Quer dizer, não estou falando de computação nem de nada. E tem gente que quer forçar a barra; por quê? Porque às vezes tem uma deficiência, tem alguma coisa... e aí vira uma muleta, não é? Mas aí o quê que acontece? Em todos os projetos, se faz amizade; quer dizer, por conta disso; aí a amizade, ela emerge como uma confiança e tal.
\end{abstract}

Ora, a gestão nos faz uma queixa quanto a um tipo de comportamento sistematicamente reproduzido por um grupo que, por sua vez, não estaria respondendo aos instrumentos de intervenção utilizados. Ou seja, reconhecida certa recorrência relacional indesejada, recursos foram direcionados para um objetivo apontado. No caso, uma consultoria especializada foi contratada; um programa foi concebido e aprovado como decorrência de trabalho e negociação; houve a execução desse plano: workshops, cartazes de endomarketing, formação de grupos de trabalho, reuniões de discussão, planos e metas secundários etc. Contudo, os objetivos iniciais não teriam sido atingidos minimamente.

A pesquisa passava, necessariamente, pelo exame dos documentos formais que fizessem referência, direta e indireta, ao problema levantado vis-à-vis a coleta resultante do procedimento de observação participante. Um conjunto de dados coletados dialogicamente que balizavam a atuação do estrato social em análise, em suas subdivisões, papéis e prerrogativas, individuais e coletivas - organograma, missão, visão, planos, mapeamento de processos, enfim, todos os registros funcionais que dessem suporte aos elementos de intencionalidade, consensualidade ou 
normatividade; mais tarde, confrontados com os discursos em busca dos elementos de estrategicidade.

Por outro lado, sempre que o método aponte para a participaçãoefetiva da direção no conjunto-de-ação estigmatizado, seja como iniciadora, seja mantenedora da ação, o foco se voltava para o outro pólo da relação. Assim encaminhado, surge não só uma possibilidade de resolução de baixíssimo custo social da problemática conflituosa, incluído aí o financeiro, mas também da melhoria significativa das condições de sociabilidade local. Isso, pelo simples fato de que o combate a contextos de ação específicos em situações de assimetria de prerrogativas - como é o caso entre gestão e subordinados -, imputando plena responsabilidade àquele que se limita a responder à estrutura "dominante", apresenta potencial para configurar, senão uma situação de violência, ao menos, de estresse. Um intervalo relacional que não interessava a ninguém. Ou seja, o diagnóstico tradicional que imputa todo problema que não consegue explicar, normal e repetidamente, a problemas com a comunicação ou com o treinamento, nesse caso, apenas revelaria seus limites, provenientes da matriz funcionalista, por ignorar elementos explicativos não apreensíveis a partir desse instrumental. Destarte, no caso empírico em análise, ação e discurso precisariam ser analisados comparativamente.

Mesmo passado um ano e prestes a ser reeditado, ainda subsistiam diversos cartazes do programa "Meu cliente, meu amigo" nas paredes da empresa. Eram em cores escuras e tons difíceis de definir, com logotipo padronizado (ver slides abaixo) e frases do tipo: "A missão de todos os profissionais da empresa é conquistar e reter clientes". O exame de conteúdo revelou perfeita sintonia com os preceitos da mercadologia tradicional (KOTLER, 1990), tendo em vista o que o estudante encontraria em seus livros-texto. Por outro lado, não parecia haver qualquer processo de adequação, em termos da alteridade, do público alvo: marca, mercado, cadeia de valor, eficácia coletiva etc. Todos referem-se a preocupações derivadas de visão de mundo específica, mas que remete o ouvinte desavisado ao senso comum. 


\section{Estimular a aproximação da empresa com os clientes e levantar as ações a serem tomadas em busca da melhoria contínua desse relacionamento.}

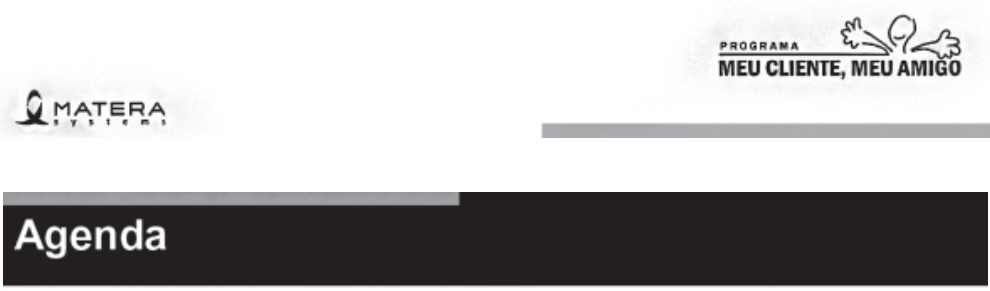

- A importância da MARCA

- O mercado de TI

- O profissional de TI (cliente)

- O fornecedor de TI ideal

- Compromissos Profissionais

- Eficácia Organizacional

- Atendimento a Clientes 


\section{A importância da MARCA}

- Marca não é um nome ou logotipo. É a somatória de percepções e sentimentos dos consumidores em relação a um produto, serviço ou empresa

- Marca pertence aos consumidores

- É formada de percepções e não de intenções

- Quanto mais diferenciado, relevante, conhecido e estimado forem os valores de uma Marca, mais forte será seu patrimônio

- Marca forte: atrai mais consumidores, fideliza clientes, protege da concorrência, assegura mais vendas e garante margens

QMATERA

\section{O fornecedor de TI ideal}

\begin{tabular}{l|l}
\hline \multicolumn{1}{|c|}{ SEGURANÇA } \\
Eficiência tecnológica \\
Solidez da empresa \\
Pouca rotatividade \\
Capacidade financeira \\
Conhecimento no mercado \\
Ética \\
Confiabilidade
\end{tabular}$\quad$\begin{tabular}{l}
\multicolumn{1}{|c}{ FOCO NO CLIENTE } \\
(e no seu profissional de TI) \\
Conhecimento do negócio \\
Rapidez de atendimento \\
Boa customização \\
Bom relacionamento \\
Demonstração de interesse \\
Treinamento \\
Suporte \\
Aconselhamento
\end{tabular}

QMATERA

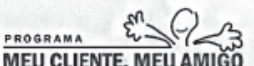


| 28 |

Etnografia customizada: tempo e espaço...

Os trinta slides do workshop inicial evidenciam um conteúdo que, mesmo refletindo os objetivos da gestão da MATERA, não vai de encontro às preocupações ou à linguagem do público descrito no item anterior, alvo do programa. $\mathrm{Na}$ verdade, atém-seà explanação de princípios gerais, disciplinarmentefocados, parecendo contar, à priori, com uma espécie de voluntarismo militante do pessoal das engenharias no que se refere à necessária instrumentalização dos conceitos ali contidos. Mais ainda, sugere não lidar com questões concretas, que sensibilizariam sua plateia. Pessoas que gastam parte significativa de seu tempo para estarem up-to-date com todas as novidades em TICs, e que se identificam com a MATERA por isso.

Mesmo com essa ordem de limitações, pareciam prontos a tirar leite de pedra. Foi assim que chegaram a efetuar traduções singelas como: "todo mundo sabe que tem que tratar bem cliente", "tem de ser educado", "a gente sabe quando é frescura", "a gente tira sarro, mas na hora $\mathrm{H}$ sabe o que tem de fazer". Por outro lado, compensavam esse estado de coisas com humor ácido. Este era dirigido, principalmente, para a logomarca da campanha, que estaria mostrando um cliente sem olhos, com boca e braços desproporcionais e vistos ora como assustadores ora como repulsivos, querendo um abraço pegajoso. Até uma camiseta jocosa fora elaborada à época.

Em suma, a apresentação buscava mudar um comportamento tido como característico de "computeiro", de não adequação, replicando a ação indesejada, embora sob outra linguagem hermética, agora, estranha ao próprio local. E assim, simplesmente, a empresa não realizou um encontro entre discurso e prática: não demonstrou arriscar-se ao contato.

Alternativamente, e em conformidade com os padrões culturais descritos, a mudança poderia ter sido iniciada com alguma sorte de diálogo ao invés do simples discurso em mercadologia. Afinal, antenados e ligados às novidades em TI, não se furtam em fornecer elementos conceituais formadores de sua visão de mundo, como que, reafirmando sua identidade. Foi assim que surgiu o termo "Agile Manifesto". Mais tarde, havendo 
explorado a pista, pude encontrar mais detalhes. Foi dessa maneira que acabei percebendo que a "moda" era, ou ainda estava por ser, Agile (http://agilemanifesto.org/):

\section{Principles behind the Agile Manifesto}

We follow these principles:

Our highest priority is to satisfy the customer through early and continuous delivery of valuable software.

Welcome changing requirements, even late in development. Agile processes harness change for the customer's competitive advantage.

Deliver working software frequently, from a couple of weeks to a couple of months, with a preference to the shorter timescale.

Business people and developers must work together daily throughout the project.

Build projects around motivated individuals. Give them the environment and support they need, and trust them to get the job done.

The most efficient and effective method of conveying information to and within a development team is face-to-face conversation.

Working software is the primary measure of progress.

Agile processes promote sustainable development.

The sponsors, developers, and users should be able to maintain a constant pace indefinitely.

Continuous attention to technical excellence and good design enhances agility.

Simplicity--the art of maximizing the amount of work not done-is essential.

The best architectures, requirements, and designs emerge from self-organizing teams.

At regular intervals, the team reflects on how to become more effective, then tunes and adjusts its behavior accordingly. 
|30 |

Etnografia customizada: tempo e espaço...

O texto acima demonstra não só um caminho de cooperação com o cliente, mas também quanto ao trabalho coletivo. Além de explícito, apela àqueles corações em especial, que pareciam acolhê-lo:
É, Agile Manifest! [...] É muito interessante... [...] É simples; uma delas é: você tem que privilegiar a interação entre as pessoas [...] privilegiar as pessoas em detrimentos das ferramentas. Os caras falam isso! Mas aí você pode falar: bom, mas o que isso quer dizer? Isso quer dizer muitas coisas. Está querendo dizer o seguinte: se você não tiver um relacionamento bom, cara, não adianta ficar fazendo uma ferramenta que aperta um botão lá e... abre e fecha uma porta... e sai em uma caixa, sabe?

Um achado que, dialogicamente, fazia a questão inicial voltar-se para o outro elo da relação, no caso, a gestão. E isso, segundo o método, porque nossa questão apenas será elucidada com o aprofundamento investigativo junto aos dois segmentos mais diretamente implicados no conjunto-de-ação recortado para análise. Afinal, se o discurso da gestão, e sua intencionalidade manifesta em programas, direcionava nossa atenção para o segmento das engenharias, agora, ela se voltava para a direção da empresa. Enfim, parecia haver uma tendência, um padrão emergente a ser explorado e incentivado pela gestão. Ou mesmo, um típico "problema de comunicação": claro sinal de limite à análise exclusivamente funcionalista.

Antes de prosseguir, porém, vale um esclarecimento metodológico. A presenteexposiçãosepara artificialmenteoselos da rede social analisada. Trata-se de mero artifício expositivo, visando maior clareza que a alcançada por meio da reprodução cronológica da atividade de pesquisa. Na prática, o desenvolvimento dialógico segue itinerário específico, sem tantas possibilidades alternativas. Assim, cada pergunta gera a necessidade de uma resposta para que a troca possa prosseguir e resulte em entendimento compartilhado. 
Um ir e vir esclarecedor, que aproxima elos de rede inicialmente apresentados como díspares, mas que a familiaridade vem ensinar tratar-se de uma mesma e única realidade. Retomemos o diálogo, ouvindo agora a institucionalidade formal.

O site apresentava a MATERA como "uma empresa para o futuro", assim descrita em seu "perfil":

A MATERA Systems iniciou suas atividades em 1987. Ao longo de mais de 20 anos de história a empresa cresceu, expandiu seus mercados sem, no entanto, deixar de lado características que foram fundamentais para seu sucesso.São marcas registradas da empresa o constante investimento em métodos e processos, bem como a preocupação com a capacitação de seus profissionais.

A qualidade na prestação de serviços e o reconhecimento por parte dos clientes proporcionam relacionamentos duradouros e são os principais impulsionadores do crescimento da empresa. Procurando aliar excelência técnica com o conhecimento de negócios, os produtos da MATERA Systems consolidaram-se em importantes mercados. E alinhada com os movimentos de globalização da economia, a empresa também explora oportunidades no exterior e concentra esforços na exportação de seus serviços de desenvolvimento offshore.

A história da MATERA Systems confirma sua vocação para o crescimento e a solidez, mantendo sempre o foco nos clientes e na satisfação de necessidades cada vez mais desafiadoras.

Os dois trechos em negrito (grifo nosso) dizem respeito ao objeto de estudo da pesquisa. Do primeiro, obtemos o funcionamento atual das estruturas sociais internas, resultado de decisões passadas, emendadas duas vezes com a conjunção 
coordenada aditiva " $\mathrm{e}$ "11. Quanto a isto, o trecho "e o reconhecimento por parte dos clientes proporcionam relacionamentos duradouros $\mathrm{e}^{\prime \prime}$ parece ter sido adicionado posteriormente; do segundo, uma preocupação relativamente atual, que vem ocupando a capacidade diretiva da MATERA quanto a um encaminhamento seguro. Conjuntamente, demonstram mudança na visão estratégica e, consequentemente, foco: de processos para clientes. O "perfil" acima corrobora a existência de uma construção de significado pretérito mesclada com o presente, mas sem composição: um novo texto não foi produzido, mas seguidamente emendado.

Mais evidente ainda foi o documento de "planejamento estratégico" da empresa, balizador interno oficial de todas as ações significativas. Era dividido em quatro grandes blocos, cada qual guiado por um conjunto de "métricas" (metas ou indicadores). Sua análise sugere haver uma relação causal, nos moldes de um fluxograma invertido, tendo como grupo de variáveis mais independentes "Aprendizado \& Cresimento", no sentido de uma contínua ampliação do leque de competências internas. Logo em seguida viria "Processos Internos", que por sua vez influenciaria um agregado denominado "Cliente", que finalmente causaria os resultados do grupo "Financeiro", tido como o conjunto de variáveis mais dependentes de toda a cadeia:

\footnotetext{
${ }^{11}$ Orações aditivas expressam ideia de acréscimo ou adição à oração anterior.
} 


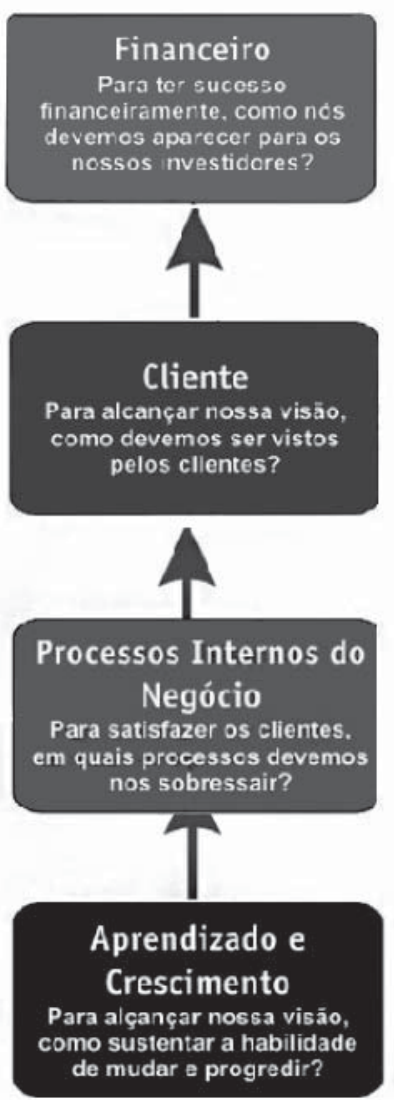

A pesquisa também averiguou, a partir de fontes internas documentadas, que a origem do instrumento estruturador do desenho acima fora desenvolvido originalmente por dois professores de Harvard (Robert Kaplan e David Norton), o Balanced Scorecard (BSC) ${ }^{12}$. Adaptando os agregados do desenho acima à proposta teórica original, teríamos:

${ }^{12}$ Aproximadamente 11,5 milhões de ocorrências para "Balanced Scorecard" no Google. 


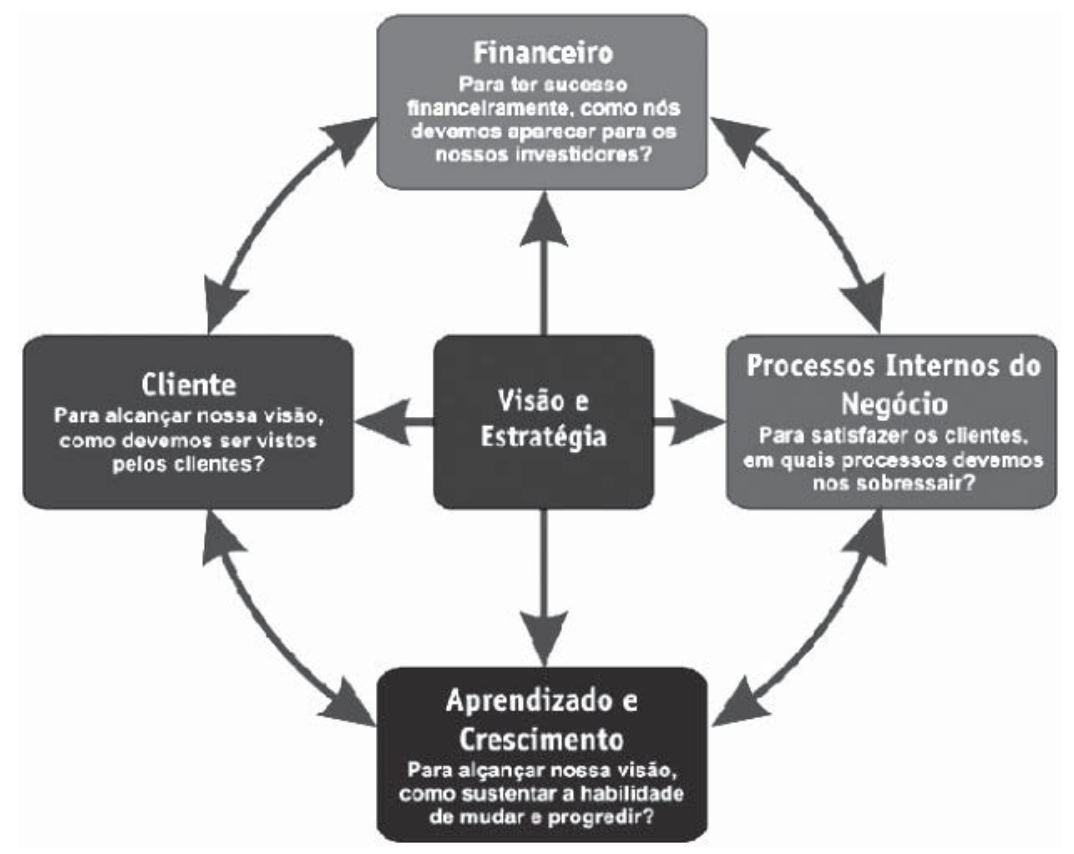

A maneira com que o modelo foi traduzido, da teoria para a prática, abre a possibilidade investigatória da análise comparativa - entre o inicialmente formulado e o efetivamente incorporado. Quanto a isso, no que mais salta aos olhos, o modelo original não contempla a causalidade entre os agregados, mas a interrelação. Porém, a manifestação local do modelo estabelece um agenciamento específico, em cadeia. Mais ainda, o detalhamento desses agregados traz uma série de métricas relacionadas pela mesma lógica.

Nesse sentido, averiguada a característica tecnomeritocrática como um dos traços identitários centrais àquele lugar, diacronicamente, posicionar "clientes" como mera consequência causal ocupava temporalidade anterior às inadequações relatadas pela gestão. Ou seja, não apenas a valoração estava hierarquicamente estabelecida, como encontrava plena possibilidade de engajamento daqueles profissionais reverenciadores do conhecimento específico, 
coadunando-se à supremacia em "Aprendizado \& Crescimento". Este fora colocado como causa primária de todas as metas, encontrava lugar de destaque na organicidade local, em composição com os objetivos divulgados e premiados pela gestão. Isso torna possível entender o tipo de escolha que qualificou o comportamento daqueles jovens frente à clientela externa às engenharias.

Destarte, do ponto de vista do sujeito, sendo o traço "tecnomeritocrático" anterior à tendência "Agile", ainda em formação, não causa espanto supor pela acomodação à diretriz organizacional estruturante. De resto, já estava ali "instalada" e, especificamente, estampada em diversas ferramentas gerenciais, mas especialmente no "Planejamento Estratégico", documento balizador que perpassava todo organograma ao integrar as metas individuais e departamentais com a visão oficial da empresa, originando assim toda uma série de documentos e instrumentos auxiliares.

\section{O processo de tradução da teoria nativa}

Etnografar o exótico sempre significou o estudo prévio do idioma nativo, sem o que o contato ficaria extremamente prejudicado. Afinal, como descrever categorias locais sem sequer entender a linguisticalidade presente no discurso do informante?

Desde os desenvolvimentos em etnologia até a teoria interpretativista (sem mencionar os pós-modernos), não faltam alertas quanto aos perigos da classificação apressada de categorias antropológicas. Assim, seja ao discutir discurso e referência (PARKIN, 1996), seja ao problematizar o processo de tradução (GEERTZ, 2002), o relativismo metodológico reza estranharmos mesmo aquilo que julgamos conhecer. Contudo, a questão ganha mais vulto ao estudarmos uma cultura próxima à nossa (CARDOSO, 2004). Um contexto inconteste para a necessidade de movimento estranhamento-familiaridade, desenvolvido como corolário, para cobrir todos os aspectos relevantes à descrição e análise das categorias pesquisadas. Um processo no qual, dentre o outras coisas, 
o pesquisador deve despojar-se de seus significados e preconceitos. Sem esses cuidados, o diálogo é prejudicado e o entendimento mutuamente dificultado.

A pesquisa revelou que mesmo o conceito de "cultura" é, no contexto do locus, uma categoria de entendimento, cuja heteroglossia apresenta a primeira armadilha para o etnógrafo. Mais ainda que, na gênese do problema, enquanto conceito, podemos notar a disputa em meio à diversidade de formações profissionais e suas disciplinas de referência. Este último tópico discutirá o processo de tradução do termo "cultura", da teoria nativa para a teoria do pesquisador.

Enquanto a cultura vem sendo objeto de estudo da antropologia por mais de um século, pode-se perceber certa apropriação do termo por outras áreas e disciplinas, especialmente, a partir do final do século passado. Assim, toda uma literatura ${ }^{13}$, que inicialmente poderia ter sido considerada mero modismo, terminou por tomar corpo, até o ponto de ensejar nova área na teoria da administração (TGA), a do Desenvolvimento ou Comportamento Organizacional (DO) (CHIAVENATO, 1999; MOTTA e VASCONCELOS, 2006).

A pesquisa averiguou que o "conceito de cultura" desenvolvidojunto ao lugar de pesquisa era coerente à reformulação em TGA. A gerente de RH, psicóloga de formação, era a portavoz e autoridade na questão. Portanto, a dificuldade inicial relacionava-se ao entendimento em meio à constante utilização do termo, no diálogo pesquisador-gerente, pelo ator instituído para o contato.

Enquanto o conceito de cultura me remetia à fluidez de entendimentos quanto à realidade vivida e seus elementos em interação, um resultado de pesquisa; demorei a perceber que meus interlocutores o tinham como algo dado e a priori, portanto, prévio à pesquisa. Desse modo, à medida que entendia a cultura como fator de condicionamento das estruturas sociais; os nativos

\footnotetext{
${ }^{13}$ Sendo Schein (1985) o de maior repercussão.
} 
tratavam-na como elemento ligado às mudanças trazidas por consultorias contratadas a peso de ouro.

As discrepâncias apontam para uma inversão de significado: enquanto a etnografia parte da relatividade para encontrar condicionantes, padrões dominantes e emergentes; a apropriação utilizada localmente partia de uma série de características predefinidas a serem injetadas através de (re)alocações, que permitiriam alcançar "resultados" tidos como desejáveis pela direção ${ }^{14}$.

Metodologicamente, a análise funcional não tem como perceber as implicações contextuais relatadas pela pesquisa, dado o limite conceitual. Mais ainda, pode ocorrer uma série de implicações políticas, desdobrando-se em problemas operacionais, como foi o caso da MATERA.

A conceituação em cultura advinda da TGA e encontrada na empresa, ao trabalhar exclusivamente com elementos funcionais, não tem como desembaraçar-se da utilidade mítica. Isso porque, mostra-se um instrumento especialmente adaptável a culturas políticas patriarcais e hierárquicas, que clarificam quem manda e quem obedece, vencedores e perdedores. Quanto a essa possibilidade, o termo "cultura organizacional" remete à prática retórica, utilizada tanto como defesa quanto ataque, mas que aponta para um "buraco negro", onde o uso efetivo vincula-se a prerrogativas políticas para apontar "culpa" ou "sucesso", individual ou coletivo. Do mesmo modo, "liderança", outro termo ligado à DO da TGA, ou a falta dela, viria a calhar em situações junto às quais se julgue necessário, ou conveniente, individualizar o resultado, apontando um culpado ou exaltando uma individualidade junto à baixa gerência.

Sempre haveria vilões a serem excluídos e heróis

\footnotetext{
${ }^{14}$ Enfoques decompõem a realidade organizacional em três grandezas ou áreas causais: estrutura, processos e resultado (HALL, 2004), em aparente adaptação ao modelo Estrutura-Conduta-Desempenho (SCHERER e ROSS, 1990).
} 
reverenciados, conforme o subjetivismo político de quem tenha poder para tal. Assim, a utilização dos conceitos funcionais de liderança e de cultura, potencialmente, é indissociável à conotação política. Aliás, o tratamento em separado para os dois conceitos, em DO, evidencia descrições de atributos estáticos ligados à personalidade ou ao grupo, conforme o caso, que os possuiria ou não. E consubstancia cada qual, um "perfil de liderança" e uma cultura disso ou daquilo, em acordo às características em voga.

Especialmente no que diz respeito ao instrumental proposto pela tese, que referencia este artigo, a aplicação do enfoque tradicional, exclusivamente funcionalista, tende a deixar a organização muito aquém do que seria razoável à criação e manutenção dos propalados ambientes culturais criativos e inovadores. Ao contrário, a possível disseminação de posturas totalizantes, que redundam em marginalizar o diverso, teria potencial para inibir o exercício de novas construções de significado a partir das atividades coletivas. Isso, ao tolher a pessoa ou grupo da expressão de suas ideias, principalmente naquilo que seria mais produtivo e gerenciável, a interlocução. Afinal, quais traços culturais seriam alimentados num ambiente em que a "verdade" viesse da posição hierárquica, não permitindo sequer discussão com o mainstream? A resposta parece fácil e tem expressão na cultura popular: tomada a decisão quanto a uma nova "norma" até então estranha ao meio, manda quem pode, obedece quem tem juízo; afora isso, restam@s louc@s e @s criador@s de caso, sem capacidade de discernimento.

\section{Bibliografia}

BARNES, J. A. Redes sociais e processo político. In. FeldmanBianco, B. Antropologia das sociedades contemporâneas Métodos, SP, Global. 1969.

CASTELLS, M. O Poder da Identidade. SP: Paz e Terra. 1988.

CHIAVENATO, I. Introdução à Teoria Geral da Administração. SP: 
Makron Books. 1999.

D'ASCENZI, L. Cultura e Inovação em Organizações: Proposta de desenvolvimento etnográfico a partir de estudo em elos da cadeia de valor de uma pequena software house de Campinas/SP. Unicamp, Tese de Doutorado em Ciências Sociais. 2010.

GEERTZ, C. Saber Local. Petrópolis: Vozes. 1998.

FOUCAULT, M. Microfísica do poder. SP: Graal. 2003.

HALL, R. H. Organizações: Estruturas, processos e resultados. SP: Pearson. 2004.

KOTLER, P. Administração de Marketing. SP: Atlas.1990.

MOTTA, F. C. P.; VASCONCELOS, I. F. G. Teoria Geral da Administração. SP: Cengage. 2006.

PARKIN, R. Genealogy and category: An Operational View. L'Homme 139. 1996.

RUBEN, G. Teoria da Identidade: Uma Crítica. In. Anuário Antropológico/ 86, RJ: Tempo Brasileiro-UNB. 1988.

SAHLINS, M. Ilhas de História. RJ: Zahar. 1990.

SIMON, H. A. Comportamento Administrativo. (mimeo) Rio de Janeiro: Editora da FGV. 1979.

SCHEIN, E. Organizational Culture and Leadership. San Francisco: Jossey-Bass. 1985.

SCHERER, F.; ROSS. Industrial Market Structure and Economic Performance. Boston: Houghton. 1990. 